\title{
Reductive immobilization of perrhenate in soil and groundwater using starch-stabilized ZVI nanoparticles
}

\author{
LIU HongFang ${ }^{1,2}$, QIAN TianWei ${ }^{2^{*}} \&$ ZHAO DongYe ${ }^{1^{*}}$ \\ ${ }^{1}$ Department of Civil Engineering, 238 Harbert Engineering Center, Auburn University, AL 36849, USA; \\ ${ }^{2}$ Institute of Environmental Science, Taiyuan University of Science and Technology, Taiyuan 030024, China
}

Received May 16, 2012; accepted July 20, 2012; published online September 6, 2012

\begin{abstract}
Perrhenate $\left(\mathrm{ReO}_{4}^{-}\right)$was used as nonradioactive surrogate for the radionuclide pertechnetate $\left({ }^{99} \mathrm{TcO}_{4}^{-}\right)$to investigate the potential of using starch-stabilized zero valent iron (ZVI) nanoparticles for reductive immobilization of pertechnetate in soil and groundwater. Batch kinetic tests indicated that the starch-stabilized ZVI nanoparticles were able to reductively remove $\sim 96 \%$ of perrhenate $(10 \mathrm{mg} / \mathrm{L})$ from water within $8 \mathrm{~h}$. XRD analyses confirmed that $\mathrm{ReO}_{2}$ was the reduction product. A pseudo-first-order kinetic model was able to interpret the kinetic data, which gave a pseudo first order rate constant $\left(k_{\text {obs }}\right)$ value of $0.43 \mathrm{~h}^{-1}$ at $\mathrm{pH} 6.9$ and room temperature $\left(25^{\circ} \mathrm{C}\right)$. Increasing solution $\mathrm{pH}$ up to 8 progressively increased the reaction rate. However, highly alkaline $\mathrm{pH}$ (10) resulted in much inhibited reaction rate. Consequently, the optimal $\mathrm{pH}$ range was identified to be from 7 to 8 . Increasing solution temperature from 15 to $45^{\circ} \mathrm{C}$ increased $k_{\text {obs }}$ from 0.38 to $0.53 \mathrm{~h}^{-1}$. The classical Arrhenius equation was able to interpret the temperature effect, which gave a low activation energy value of $7.61 \mathrm{~kJ} / \mathrm{mol}$. When the $\mathrm{ReO}_{4}^{-}$-loaded loess was treated with the stabilized nanoparticles suspension $([\mathrm{Fe}]=560 \mathrm{mg} / \mathrm{L})$, the water leachable $\mathrm{ReO}_{4}^{-}$was reduced by $57 \%$ and nearly all eluted Re was in the form of $\mathrm{ReO}_{2}$. This finding indicates that starch-stabilized ZVI nanoparticles are promising for facilitating in situ immobilization of $\mathrm{ReO}_{4}^{-}$in soil and groundwater.
\end{abstract}

heavy metals, nanoparticles, perrhenate, pertechnetate, radionuclides, reductive immobilization, zero valent iron

Citation: Liu H F, Qian T W, Zhao D Y. Reductive immobilization of perrhenate in soil and groundwater using starch-stabilized ZVI nanoparticles. Chin Sci Bull, 2013, 58: 275-281, doi: 10.1007/s11434-012-5425-3

The past cold war era and recent rapid development of nuclear energy have resulted in a legacy of widespread contamination of soil and groundwater with radionuclides [1]. Technetium-99 is one of the most important radioactive wastes. The half life of technetium-99 is $2.13 \times 10^{5}$ years [2]. Under oxic groundwater conditions, technetium-99 occurs in the anionic form of pertechnetate $\left(\mathrm{TcO}_{4}^{-}\right)$or $\mathrm{Tc}(\mathrm{VII})$. Because of its high water solubility and the mobility in the environment, Tc(VII) has been detected widely in soil and groundwater, and thus, is considered a major environmental threat. On the other hand, when Tc(VII) is reduced to the sparingly soluble form of Tc(IV), the mobility and availability of Tc are substantially reduced. Therefore, a potentially effective method for remediating Tc-contaminated soil

*Corresponding authors (email: twqian@ sina.com; zhaodon@auburn.edu) and groundwater is immobilization by reducing $\mathrm{Tc}(\mathrm{VII})$ to Tc(IV).

Many researchers have focused on applying various adsorptive materials to confine the mobility of pertechnetate from radioactive waste repositories [3-6]. However, these macroscopic materials are not deliverable into the contaminant plumes in the subsurface, and thus, are not applicable for in situ immobilization of Tc(VII) in soil and groundwater.

In recent year, ZVI nanoparticles have been widely studied for remediation of soil and water contaminated with chlorinated solvents as well as toxic metals [6-9]. Compared with commercial iron powder or granular iron particles, ZVI nanoparticles offer larger surface area and exhibit much faster reaction kinetics [9-13]. In addition, truly discrete nanoparticles offer the unique advantage that the nanoparticles maybe directly delivered into the contaminant 
plumes in the subsurface and facilitate in situ destruction or immobilization of contaminants in deep aquifers. While such in situ technology holds the promise to fill major technology gap and revolutionize the conventional remediation practices, ZVI nanoparticles without a stabilizer tend to agglomerate rapidly, resulting in the formation of micro- to millimeter scale aggregates, thereby losing the unique reactivity and soil deliverability.

To prevent ZVI nanoparticles from agglomeration, a number of particle stabilization techniques were reported [14-17]. He and Zhao [14,16,17] reported a new method for synthesizing stabilized ZVI nanoparticles by using some lowcost and environmentally benign polysaccharides (starch and cellulose) as a stabilizer. The stabilized nanoparticles displayed much improved physical stability, soil mobility and reductive reactivity than non-stabilized ZVI particles. Consequently, polysaccharide stabilized ZVI nanoparticles hold the potential to facilitate in situ reductive remediation of various redox sensitive contaminants ranging from chlorinated solvents to various toxic metals including radionuclides such as ${ }^{99} \mathrm{Tc}$.

The goal of this present work was to preliminarily test the effectiveness of starch-stabilized ZVI nanoparticles for reductive immobilization of ${ }^{99} \mathrm{TcO}_{4}^{-}$in soil and groundwater. To ease the experimental work, $\mathrm{ReO}_{4}^{-}$was used as a chemical analogue of $\mathrm{TcO}_{4}^{-}$. Because the two anions share very similar physical and chemical properties, and because of the availability and non-radioactive nature, $\mathrm{ReO}_{4}^{-}$has been commonly used as an surrogate for $\mathrm{TcO}_{4}^{-}[18,19]$. The specific objectives were to: (1) examine the $\mathrm{ReO}_{4}^{-}$reduction kinetics by starch-stabilized ZVI nanoparticles through controlled batch experiments; (2) determine effects of various parameters such as $\mathrm{pH}$, temperature, and initial concentration on the reduction efficacy; and (3) preliminarily test the effectiveness of the starch-stabilized ZVI nanoparticles for in situ immobilization of $\mathrm{ReO}_{4}^{-}$in a contaminated Chinese loess through bench-scale column elution experiments.

\section{Materials and methods}

\subsection{Materials}

Chemicals of analytical grade or higher were used in this work. $\mathrm{Fe}(\mathrm{II})$ sulfate heptahydrate $\left(\mathrm{FeSO}_{4} \cdot 7 \mathrm{H}_{2} \mathrm{O}\right)$, sodium borohydride $\left(\mathrm{NaBH}_{4}\right)$, potassium perrhenate $\left(\mathrm{KReO}_{4}\right)$ were obtained from Sinopharm Chemical Reagent Limited Company (Shanghai, China). A water-soluble starch was procured from Alfa Aesar, Wall Hill, (MA, USA). All solutions were prepared with ultrapure deionized (DI) water $\left(18.2 \Omega \mathrm{cm}^{-1}\right)$.

\subsection{Preparation of stabilized ZVI nanoparticles}

The method developed by He and Zhao $[14,17]$ was adopted for preparing starch-stabilized ZVI nanoparticles. In brief, a water-soluble starch was used as a stabilizer in the preparation. The preparation was carried out in a $250 \mathrm{~mL}$ flask. Before use, deionized (DI) water and starch solution were purged with $\mathrm{N}_{2}$ for half an hour to remove dissolved oxygen (DO). $\mathrm{A} \mathrm{FeSO}_{4}$ stock solution was added to a starch solution through a burette to give a final $\mathrm{Fe}$ concentration of 560 $\mathrm{mg} / \mathrm{L}$ and a starch concentration of $0.2 \%$ (w/w). Then, $\mathrm{Fe}^{2+}$ was reduced to $\mathrm{Fe}^{0}$ using stoichiometric amounts of sodium borohydride. To ensure efficient use of the reducing agent $\mathrm{BH}_{4}^{-}$, the reactor system was operated in the absence of DO. The stabilized Fe suspension was then sealed and stored for 20 min before every use.

\subsection{Preparation of $\mathrm{ReO}_{4}^{-}$-laden loess}

The Chinese loess was obtained from an experimental field of China Institute for Radiation Protection in Yuci City, Shanxi province, located on the Loess Plateau of northern China. Prior to use, the raw loess was sieved with a $2 \mathrm{~mm}$ standard sieve. Based on particle size fractionation, the loess is made up of $78 \%$ of sand, $21 \%$ of silt and $1 \%$ of clay. Therefore, the soil taxonomy falls into the category of loamy sand. The loess contains $0.39 \%$ of soil organic matter (SOM) and was initially free of perrhenate. Perrhenate was loaded to the loess by equilibrating $1 \mathrm{~L}$ of a solution containing $433.5 \mathrm{mg} / \mathrm{L}$ of perrhenate (in $\mathrm{KReO}_{4}$ ) with $200 \mathrm{~g}$ of an air-dried loess sample in a batch reactor for 1 month at $\mathrm{pH} 5.5$, which resulted in a $55 \mathrm{mg} / \mathrm{kg} \mathrm{ReO}_{4}^{-}$uptake. The $\mathrm{ReO}_{4}^{-}$spiked loess was then air-dried and stored in a sealed bottle for subsequent experimental uses.

\subsection{Reductive removal of $\mathrm{ReO}_{4}^{-}$from water: Kinetic tests}

To probe the effectiveness of the starch-stabilized ZVI nanoparticles for reductive immobilization/removal of perrhenate, batch experiments were first carried out in homogeneous systems (i.e. in water solution of $\mathrm{ReO}_{4}^{-}$). The experiments were carried out in $200 \mathrm{~mL}$ glass vials sealed with Teflon-lined septa. The redox reaction was initiated by adding $2 \mathrm{~mL}$ of a perrhenate stock solution into $198 \mathrm{~mL}$ of a suspension of starch-stabilized ZVI nanoparticles to give a ZVI concentration of $560 \mathrm{mg} / \mathrm{L}$, an initial $\mathrm{ReO}_{4}^{-}$concentration of $10 \mathrm{mg} / \mathrm{L}$ and a starch concentration of $0.20 \mathrm{wt} \%$. Nearly zero headspace was maintained in all vials to minimize DO effect. The mixtures were placed on a shaker at $200 \mathrm{r} / \mathrm{min}$ and sacrificially sampled at pre-designed time intervals. The sampled vials were first centrifuged at 5000x $g$-force with a high-speed centrifuge (CF16RX II, Hitachi, Japan) for $15 \mathrm{~min}$, then passed through a $25 \mathrm{~nm}$ membrane filter $(0.025 \mu \mathrm{m}$ VSWP, Millipore, USA) to completely remove the nanoparticles and insoluble Re species from the solution phase. The filtrates were then analyzed for soluble $\mathrm{ReO}_{4}^{-}$remaining in the solution using an ICP-OES (Optima 
7300, Perkin Elmer, USA) to analyze the supernatants for $\mathrm{ReO}_{4}^{-}$.

\subsection{XRD analysis of reduction products}

The nanoparticles and solid reduction products of the reaction collected on the membrane were first dried under nitrogen gas. The dried samples were then ground to a homogenous mixture using a mortar and pestle, and then scanned at diffraction angles $(2 \theta)$ ranging from $10.000^{\circ}$ to $79.990^{\circ}$ with a constant step width of $0.010^{\circ}$ and a step time of $600 \mathrm{~s}$ at room temperature $\left(25^{\circ} \mathrm{C}\right)$. The XRD was operated with a Bruker D8 Discover X-ray Diffractometer (Bruker Corp., Madison, WI, USA) with a GADDS (General Area Detector Diffraction Solution) area detector, with a $\mathrm{Cu}$ target $(\lambda=1.54060 \AA)$ and a 4-bounce monochromator Ge (022). The resultant spectra were further processed by means of a semi-quantitative phase analysis software EVA to subtract background, smooth the data and search for peaks.

\subsection{Fixed-bed column test}

To test the effectiveness of the starch-stabilized ZVI nanoparticles for in situ reductive immobilization of $\mathrm{ReO}_{4}^{-}$in soil, column experiments were conducted by passing a suspension of the starch-stabilized ZVI nanoparticles through the $\mathrm{ReO}_{4}^{-}$-loaded loess packed in a column. Figure 1 shows the experimental column setup, which consisted of an HPLC pump (Series III-Acuflow), a glass column (inner diameter= $1.0 \mathrm{~cm}$ and length=15 cm; Omnifit, Cambridge, England) with adjustable headspace (Omnifit, Cambridge, England), and an automatic fraction collector (ASS100A, China). In each test, $8 \mathrm{~g}$ of the $\mathrm{ReO}_{4}^{-}$-loaded loess was packed in the column resulting in a soil bed porosity of 0.49 and a bulk bed volume of $5.8 \mathrm{~mL}$. Then, the $\mathrm{ReO}_{4}^{-}$-laden loess was treated by passing the ZVI nanoparticle suspension ([Fe]= $560 \mathrm{mg} / \mathrm{L}$ ) through the column in a downflow mode. The flow rate was kept constant at $0.1 \mathrm{~mL} / \mathrm{min}$. For compassion, control column tests were also performed in parallel using deionized water with the same background starch.

\section{Results and discussion}

\subsection{Effect of initial concentration}

Figure 2(a) shows Re (VII) reduction kinetic data in the presence of starch-stabilized ZVI nanoparticles. Reduction of perrhenate was observed within $8 \mathrm{~h}$. At the reaction steady state $(\sim 8 \mathrm{~h}), \sim 96 \%$ of perrhenate was removed from the solution.

The reduction rate of $\mathrm{ReO}_{4}^{-}$can be described by a pseudo-first-order kinetic model,

$$
v=\frac{\mathrm{d} C}{\mathrm{~d} t}=-k_{\mathrm{obs}} C
$$

where $C$ is the concentration of $\mathrm{ReO}_{4}^{-}$in water $(\mathrm{mg} / \mathrm{L}), t$ the time (h), and $k_{\text {obs }}$ the observed first-order rate constant $\left(\mathrm{h}^{-1}\right)$. Based on the kinetic data, the reaction equilibrium was reached at $\sim 8 \mathrm{~h}$. Thus, the $k_{\text {obs }}$ value was obtained by fitting the kinetic model to the experimental data up to $8 \mathrm{~h}$ rather than the entire experimental time of $12 \mathrm{~h}$ (Figure 2(b)). The similar modeling approach was applied to reduction of Cr(VI) [20] and trichloroethylene [21] by ZVI nanoparticles. Fairly good model fitting was obtained $\left(R^{2}=0.96\right)$. The modeling fitting gave a $k_{\text {obs }}$ value of $0.43 \mathrm{~h}^{-1}$. The results suggest that the starch stabilized ZVI nanoparticles allow for effective reduction of $\mathrm{Re}(\mathrm{VII})$ in environmental samples.

Figure 3 shows the powder XRD diffractogram for the reduction products at $25^{\circ} \mathrm{C}$. The results clearly indentified three distinct crystalline phases, including the reduced rhenium as $\mathrm{ReO}_{2}, \mathrm{Fe}_{2} \mathrm{O}_{3}$, and elemental $\mathrm{Fe}$. This result confirmed that the formation of the insoluble $\mathrm{ReO}_{2}$ species is the key mechanism for perrhenate removal from the aqueous phase. The formation of iron oxide can be attributed to

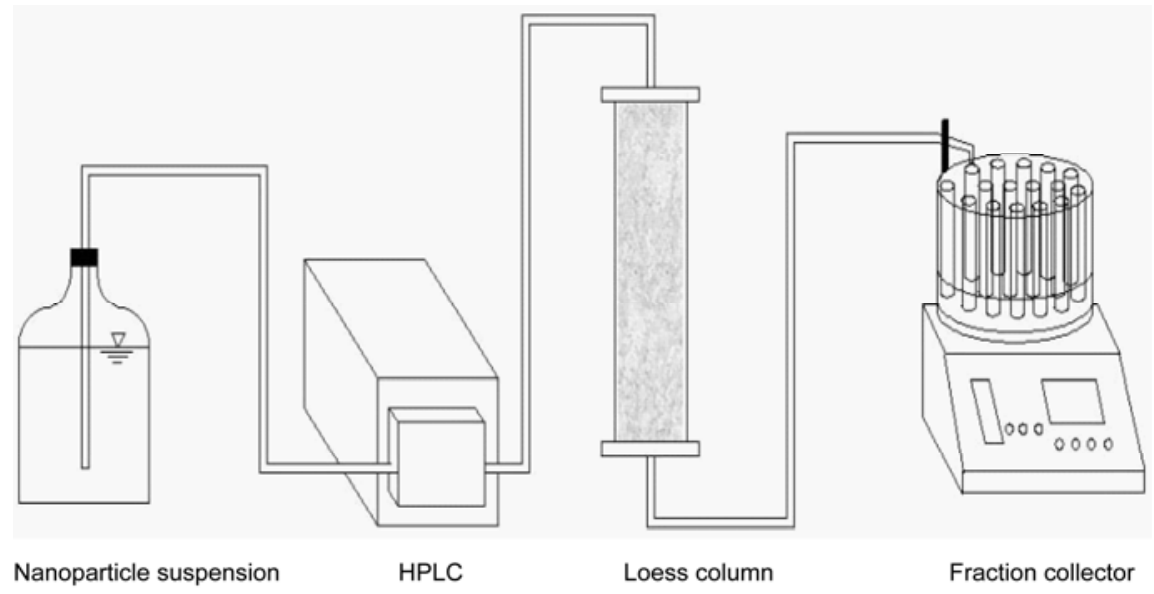

Figure 1 Schematic of the experimental setup for the column experiments. 

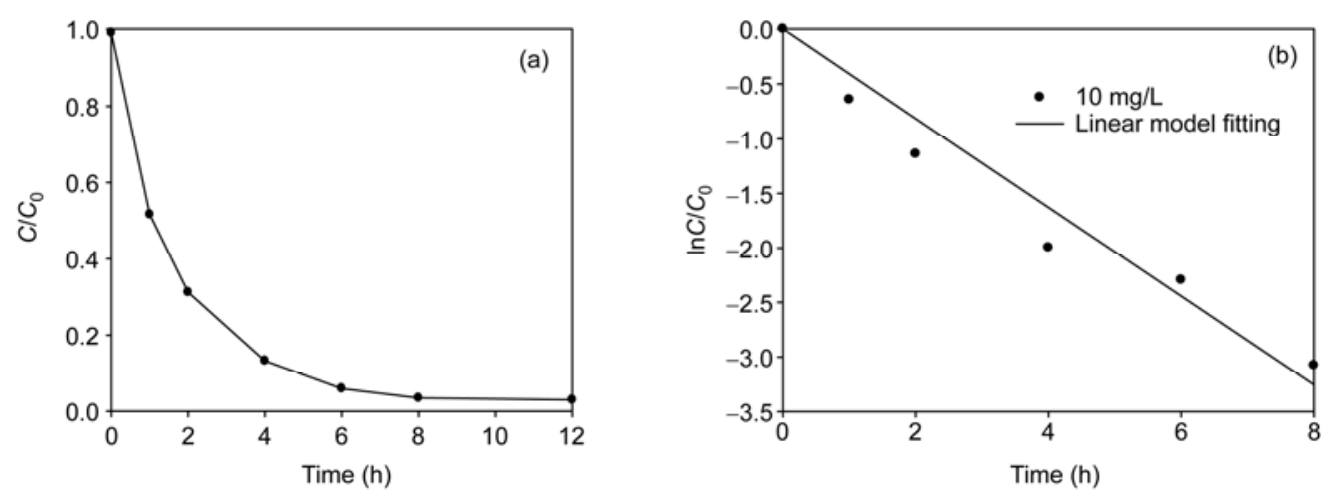

Figure 2 (a) Reduction of perrhenate as a function of time by starch-stabilized ZVI nanoparticles. (b) Fitting a pseudo-first-order model to the experimental perrhenate reduction rate data. Symbols: experimental data; Lines: model fittings. Experimental conditions: $C_{0}=10 \mathrm{mg} / \mathrm{L}$ as $\mathrm{ReO}-, \mathrm{ZVI}=560 \mathrm{mg} / \mathrm{L}$ as $\mathrm{Fe}, \mathrm{Starch}=0.2 \mathrm{wt} \%, \mathrm{pH}_{\text {initial }}=6.9, \mathrm{pH}_{\text {final }}=7.3$, Temperature $=25^{\circ} \mathrm{C}$.

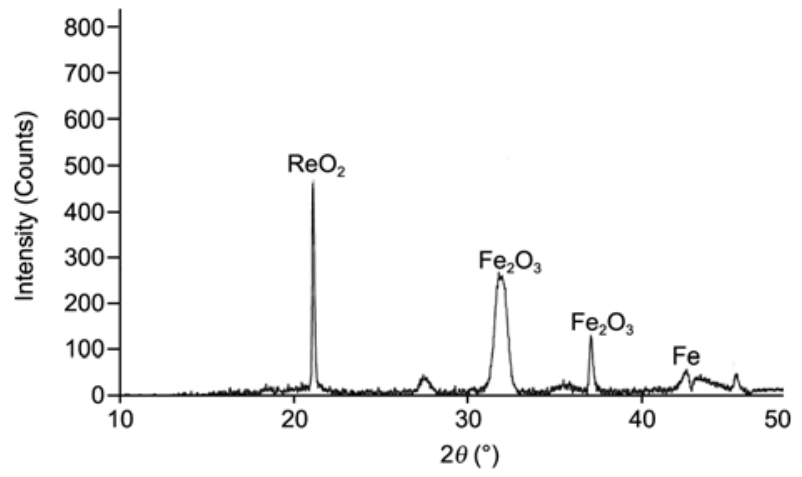

Figure 3 The X-ray diffraction pattern of the redox reaction products between ZVI and perrhenate.

oxidation of the ZVI nanoparticles by reaction with $\mathrm{ReO}_{4}^{-}$ and/or $\mathrm{H}^{+}$. Equation (2) depicts the redox reaction:

$$
\mathrm{Fe}_{(\mathrm{s})}^{0}+\mathrm{ReO}_{4(\mathrm{aq})}^{-}+\mathrm{H}_{2} \mathrm{O} \rightarrow \mathrm{Fe}_{2} \mathrm{O}_{3(\mathrm{~s})}+\mathrm{ReO}_{2(\mathrm{~s})}+\mathrm{OH}_{(\mathrm{aq})}^{-}
$$

Because of the similar chemistry between $\mathrm{ReO}_{4}^{-}$and $\mathrm{TcO}_{4}^{-}$, the same mechanism may be applied to pertechnetate, which is the ultimate target radionuclide [19]. When the reduction $\mathrm{TcO}_{4}^{-}$and $\mathrm{ReO}_{4}^{-}$are compared under environmental nitrate- and iron-reducing conditions and in the presence organic co-contaminants, researchers observed that reduction of $\mathrm{TcO}_{4}^{-}$is more easily reduced by $\mathrm{Sn}$ (II) than $\mathrm{ReO}_{4}^{-}$. Further, the researchers identified that the majority of the $\mathrm{TcO}_{4}^{-}$was reduced to particle-reactive $\mathrm{Tc}(\mathrm{IV})$ and removed from solution during nitrate reduction, and there was no chromatographic evidence of $\mathrm{Tc}(\mathrm{IV})$-organic complexes in the soil pore water. The thermodynamic favorability of $\mathrm{TcO}_{4}^{-}$ over $\mathrm{ReO}_{4}^{-}$can be easily revealed by the standard redox potential $\left(E^{0}\right)$ as shown in eqs. (3) and (4):

$$
\begin{aligned}
& \mathrm{ReO}_{4(\mathrm{aq})}^{-}+4 \mathrm{H}_{(\mathrm{aq})}^{+}+3 \mathrm{e}^{-} \rightarrow \mathrm{ReO}_{2(\mathrm{~s})}+2 \mathrm{H}_{2} \mathrm{O}_{(\mathrm{l})} \quad E^{0}=-0.548 \mathrm{~V}(3) \\
& \mathrm{TcO}_{4(\mathrm{aq})}^{-}+4 \mathrm{H}_{(\mathrm{aq})}^{+}+3 \mathrm{e}^{-} \rightarrow \mathrm{TcO}_{2(\mathrm{~s})}+2 \mathrm{H}_{2} \mathrm{O}_{(\mathrm{l})} \quad E^{0}=-0.361 \mathrm{~V}(4)
\end{aligned}
$$

The resultant $\mathrm{Tc}(\mathrm{IV}) / \operatorname{Re}(\mathrm{IV})$ oxide solids are quite stable under subsurface environmental conditions [3,5]. Physically, the precipitates can be attached to geological materials and become immobilized [22].

The ZVI nanoparticles from the borohydride reduction method may contain some residual $(\sim 4 \mathrm{wt} \%)$ of B $[23,24]$. Nikolay et al. [25] observed that the zero valent boron nanoparticles at elevated concentrations may adversely affect some aquatic microorganisms. However, the adverse effect is less likely for the starch stabilized ZVI for the following arguments: (1) $B$ in the ZVI nanoparticles is more likely in its oxides form [26], and (2) the $B^{0}$ concentration in our case is much lower.

\subsection{Effect of $\mathrm{pH}$}

Equations. (3), (4) and prior work [21] indicate that $\mathrm{H}^{+}$ions will compete for the electrons from $\mathrm{ZVI}$, and thus, $\mathrm{pH}$ is likely to affect the reduction extent and rate. To probe the $\mathrm{pH}$ effect on the reduction rate, the same kinetic experiments were conducted at an initial $\mathrm{pH}$ of 5.0, 7.0, 8.0, 10.0, respectively. At the end of each experiment, the corresponding $\mathrm{pH}$ was increased to $6.1,7.4,8.3,10.3$, respectively. In all cases, more than $90 \%$ of perrhenate removal was achieved, with the highest removal $(\sim 98 \%)$ being observed at $\mathrm{pH}$ 8.0. Based on the kinetic data, the pseudofirst-order rate constants were determined following the same model fitting procedure $\left(R^{2}>0.90\right.$ in all cases). Figure 4 plots the pseudo-first-order rate constants as a function of initial solution pH. From pH 5.0 to 8.0 , the $k_{\mathrm{obs}}$ value increased from 0.32 to $0.45 \mathrm{~h}^{-1}$, but abruptly dropped to 0.30 $\mathrm{h}^{-1}$ when the initial $\mathrm{pH}$ was raised to 10.0. Evidently, more competition from $\mathrm{H}^{+}$ions for electrons at the lower $\mathrm{pH}$ rendered reduced perrhenate reduction. Note that the $\mathrm{H}_{2}$ gas generated from $\mathrm{H}^{+}$reduction cannot effectively reduce $\mathrm{Re}(\mathrm{VII})$. When $\mathrm{pH}$ is too high, iron hydroxide precipitation would be expected. The precipitates on the surface of ZVI nanoparticles form a passivation layer, inhibiting the reduction kinetics. In addition, the solution $\mathrm{pH}$ can also affect surface 


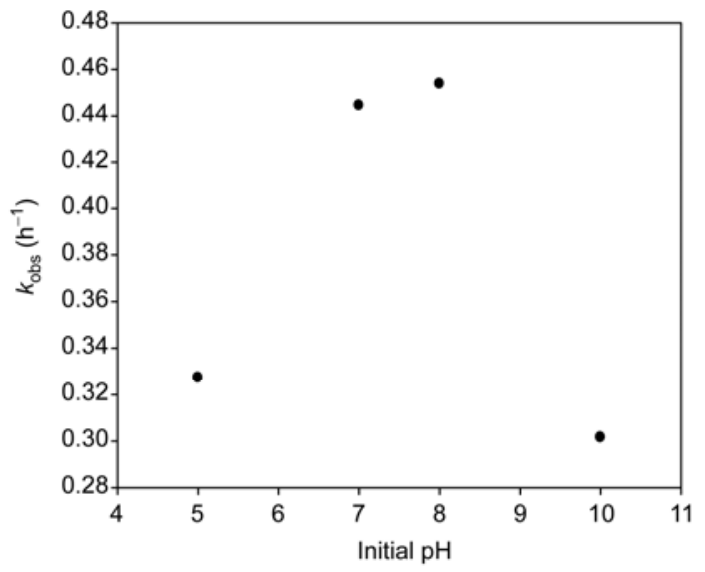

Figure 4 Effect of $\mathrm{pH}$ on the pseudo first order rate constant for $\mathrm{ReO}_{4}^{-}$ reduction by stabilized ZVI nanoparticles. Experimental conditions: $C_{0}=10$ $\mathrm{mg} / \mathrm{L}$ as $\mathrm{ReO}_{4}^{-}, \mathrm{ZVI}=560 \mathrm{mg} / \mathrm{L}$ as Fe, Starch $=0.2 \mathrm{wt} \%, \mathrm{pH}_{\text {initial }}=5.00-10.00$, $\mathrm{pH}_{\text {final }}=6.10-10.29, T=25^{\circ} \mathrm{C}$.

potential of the iron oxide shell on the ZVI nanoparticles [21], with the higher $\mathrm{pH}$ being more repulsive to the likecharged perrhenate anions. Moreover, the higher $\mathrm{pH}$ also impedes the starch's particle stabilizing power, resulting in larger particles and diminished reactivity. Furthermore, the higher $\mathrm{pH}$ renders a more negative surface potential, which repels sorptive removal if the anionic $\mathrm{ReO}_{4}^{-}$. In general, the stabilization effect of starch can be impeded at the extremely alkaline $\mathrm{pH}$ due to completion of $\mathrm{OH}^{-}$ions with starch for the surface binding sites of the nanoparticles [17].

\subsection{Effect of temperature}

Figure 5(a) shows the effect of temperature on the reductive removal kinetics of $\mathrm{ReO}_{4}^{-}$from water. It is evident that increasing temperature from 15 to $45^{\circ} \mathrm{C}$ progressively increased the removal rates although the final extent of removal was comparable (all at $>95 \%$ ). The observed reactivity enhancement of the ZVI nanoparticles by temperature is in accord with the commonly expected temperature effect on reaction rate and can be explained by the enhanced effective collision between $\mathrm{ReO}_{4}^{-}$ions and the nanoparticles. The classical Arrhenius equation can be used to interpret the temperature effect:

$$
\ln k_{\mathrm{obs}}=\ln A-\frac{E_{\mathrm{a}}}{R T},
$$

where $A$ is the pre-exponential factor constant, $E_{\mathrm{a}}$ the activation energy $(\mathrm{kJ} / \mathrm{mol}), R$ the universal gas constant $(8.314 \mathrm{~kJ}$ $\mathrm{mol}^{-1} \mathrm{k}^{-1}$ ), and $T$ the absolute temperature $(\mathrm{K})$. Table 1 gives the model-fitted $k_{\mathrm{obs}}$ values based on the kinetic data.

Figure 5(b) gives an activation energy $\left(E_{\mathrm{a}}\right)$ of $7.61 \mathrm{~kJ} / \mathrm{mol}$ and an $A$ value of 33223 for the starch-stabilized ZVI nanoparticles. These values indicate that reduction of $\mathrm{ReO}_{4}^{-}$by the stabilized ZVI nanoparticles is thermodynamically
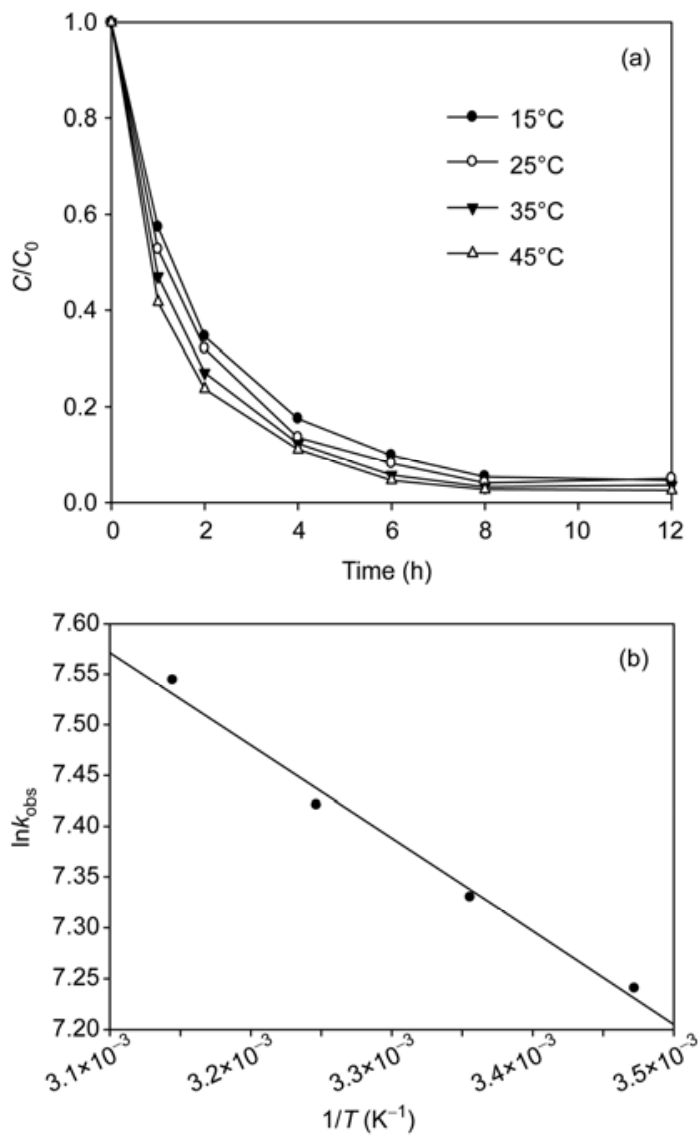

Figure 5 (a) Kinetics of perrhenate reduction by starch-stabilized ZVI nanoparticles at four different temperature levels. (b) Linearized Arrhenius plot of the observed first-order rate constant (Table 1) as a function of $1 / T$. Experimental conditions: $C_{0}=10 \mathrm{mg} / \mathrm{L}$ as $\mathrm{ReO}_{4}^{-}, \mathrm{ZVI}=560 \mathrm{mg} / \mathrm{L}$ as $\mathrm{Fe}$, $\mathrm{Starch}=0.2 \mathrm{wt} \%, \mathrm{pH}_{\text {initial }}=7.2, \mathrm{pH}_{\text {final }}=7.4-7.6$.

Table 1 Observed pseudo-first-order rate constants of perrhenate reduction by starch-stabilized ZVI nanoparticles at various temperatures

\begin{tabular}{ccc}
\hline Temperature $\left({ }^{\circ} \mathrm{C}\right)$ & $k_{\text {obs }}\left(\mathrm{h}^{-1}\right)$ & $R^{2}$ \\
\hline 15 & 0.38 & 0.97 \\
25 & 0.43 & 0.96 \\
35 & 0.46 & 0.97 \\
45 & 0.53 & 0.95 \\
\hline
\end{tabular}

favorable. The relatively low activation energy can be attributed to the small particle size, and thus, greater specific surface area and reactivity compared to non-stabilized ZVI aggregates.

\subsection{Fixed-bed column tests}

Figure 6 shows the elution histories of $\mathrm{ReO}_{4}^{-}$that was preloaded in the Chinese loess when a suspension of $560 \mathrm{mg} / \mathrm{L}$ ZVI nanoparticles or DI-water was pumped through the soil bed under otherwise identical conditions. As shown in Figure 6, the elution of $\mathrm{ReO}_{4}^{-}$with DI water displayed a much 


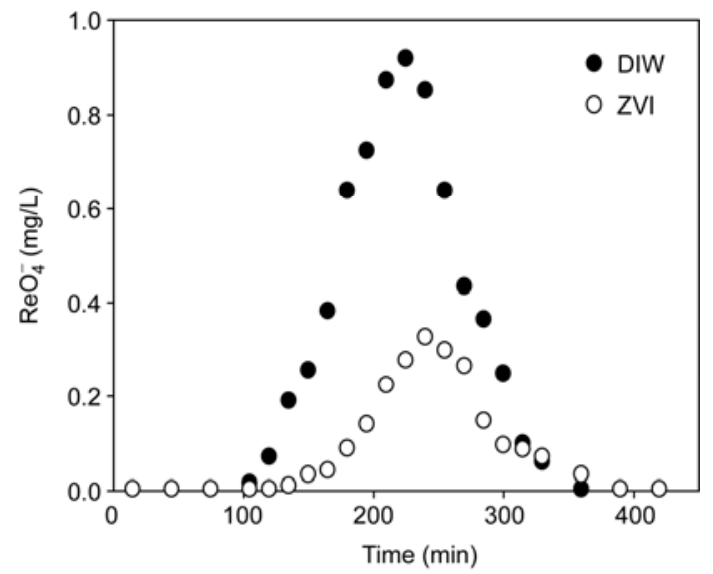

Figure $6 \mathrm{ReO}_{4}^{-}$elution histories during two separate column runs where a $\mathrm{ReO}_{4}^{-}$-loaded soil was eluted using a starch-stabilized ZVI nanoparticle suspension $([\mathrm{Fe}]=560 \mathrm{mg} / \mathrm{L}, \mathrm{Starch}=0.2 \mathrm{wt} \%)$ or DI water, pH 7.2. Empty bed contact time $(\mathrm{EBCT})=58 \mathrm{~min}$.

higher and broader peak than that with the ZVI nanoparticle suspension. Mass balance calculation revealed that DI water eluted $88 \%$ of the pre-loaded $\mathrm{ReO}_{4}^{-}$, while the ZVI suspension leached only $31 \%$, representing a $57 \%$ reduction. In the presence of starch-stabilized ZVI nanoparticles, the eluted peak concentration dropped from 9.2 to $3.3 \mu \mathrm{g} / \mathrm{L}$. Further analysis of the eluted Re species in the effluent indicated that nearly all of the eluted Re was present as the insoluble $\mathrm{ReO}_{2}$, which can be removed from the water phase through natural filtration by the soil. This preliminary observation indicates that starch-stabilized ZVI nanoparticles hold the promise for in situ immobilization of $\mathrm{ReO}_{4}^{-}$in soil and groundwater. The column tests also indicated that the starch-stabilized ZVI nanoparticles can transport through the soil bed, and thus, are likely to be deliverable to contaminated soil and groundwater to facilitate the desired in situ remediation.

\section{Conclusions}

This study preliminarily investigated the effectiveness of starch-stabilized ZVI nanoparticles for reductive immobilization of $\mathrm{ReO}_{4}^{-}$(and potentially $\mathrm{TcO}_{4}^{-}$) in soil and groundwater. Batch kinetic tests indicated that the starch-stabilized ZVI nanoparticles can effectively reduce $\mathrm{ReO}_{4}^{-}$in water and $\sim 96 \%$ of perrhenate $(10 \mathrm{mg} / \mathrm{L})$ was reductively removed from the solution phase within $8 \mathrm{~h}$. XRD analyses confirmed that the insoluble $\mathrm{ReO}_{2}$ was the reduction product. A pseudo-first-order kinetic model was able to interpret the kinetic data, which gave a $k_{\text {obs }}$ value of $0.43 \mathrm{~h}^{-1}$ at $\mathrm{pH} 6.9$ and room temperature $\left(25^{\circ} \mathrm{C}\right)$. Increasing solution $\mathrm{pH}$ up to 8 progressively increased reaction rate. However, highly alkaline $\mathrm{pH}$ (10) resulted in much inhibited reaction rate. Consequently, the optimal $\mathrm{pH}$ range was identified to be from 7 to 8 . Increasing solution temperature from 15 to $45^{\circ} \mathrm{C}$ increased reaction rate constant from 0.38 to $0.53 \mathrm{~h}^{-1}$. The classical Arrhenius equation was able to interpret the temperature effect on the reaction kinetics, which gave a low activation energy value of $7.61 \mathrm{~kJ} / \mathrm{mol}$. When the $\mathrm{ReO}_{4}^{-}$-loaded loess was treated with the stabilized nanoparticles suspension $([\mathrm{Fe}]=560 \mathrm{mg} / \mathrm{L})$, the water leachable $\mathrm{ReO}_{4}^{-}$ was reduced by $57 \%$ and nearly all eluted Re was in the form of $\mathrm{ReO}_{2}$. The findings indicate that the starch-stabilized ZVI nanoparticles are promising for in situ immobilization of $\mathrm{ReO}_{4}^{-}$in soil and groundwater, and further more detailed study is warranted.

This work was partially supported by the National Natural Science Foundation of China (41072265 and 40810152), the Science-Technology Research of Colleges in Shanxi Province (20091022), the Shanxi Provincial 100 Talents Program, China, and an Auburn University VPR's IGP.

1 Long J C, Ewing R C. Yucca Mountain: Earth-science issues at a geologic repository for high-level nuclear waste. Annu Rev Earth Pl Sc, 2004, 32: 363-401

2 Plymale A E, Fredrickson J K, Dohnalkova A C, et al. Competitive reduction of pertechnetate $\left({ }^{99} \mathrm{TcO}_{4}^{-}\right)$by dissimilatory metal reducing bacteria and biogenic Fe(II). Environ Sci Technol, 2011, 45: 951-957

3 Liang L, Gu B, Yin X. Removal of technetium-99 from contaminated groundwater with sorbents and reductive materical. Separations Technol, 1996, 6: 111-122

4 León M G. ${ }^{99} \mathrm{Tc}$ in the Environment: Sources, distribution and methods. Nucl Radiochem Sci, 2005, 6: 253-259

$5 \mathrm{Gu}$ B, Dowlen K E, Liang L, et al. Efficient separation and recovery of technetium-99 from contaminated groundwater. Separations Technol, 1996, 6: 123-132

6 Bradley W, Nagy K. Perrhenate uptake by iron and aluminum oxyhydroxides: An analogue for pertechnetate incorporation in hanford waste tank sludges. Environ Sci Technol, 2004, 38: 1765-1771

7 Dale L, Huber D. Synthesis, properties, and applications of iron nanoparticles. Small, 2005, 1: 482-501

8 Gautham J, Kanchan M, Sha S B, et al. Arsenate remediation using nanosized modified zero valent iron particles. Environ Prog, 2005, 24: 289-296

9 Zhang W X. Nanoscale iron particles for environmental remediation: An overview. Nano Res, 2003, 5: 323-332

10 Chen S S, Hsu H D, Li C W. A new method to produce nanoscale iron for nitrate removal. Nano Res, 2005, 6: 639-647

11 Joo S H, Feitz A J, Sedlak D L, et al. Quantification of the oxidizing capacity of nanoparticulate zero-valent iron. Environ Sci Technol, 2005, 38: 2242-2247

12 Yang G C, Lee H L. Chemical reduction of nitrate by nanosized iron: Kinetics and pathways. Water Res, 2005, 39: 884-894

13 Zhang M, Wang Y, Zhao D Y, et al. Immobilization of arsenic in soils by stabilized nanoscale zero valent iron, iron sulfide $(\mathrm{FeS})$, and magnetite $\left(\mathrm{Fe}_{3} \mathrm{O}_{4}\right)$ particles. Chin Sci Bull, 2010, 55: 365-372

14 He F, Zhao D Y. Preparation and characterization of a new class of starch-stabilized bimetallic nanoparticles for degradation of chlorinated hydrocarbons in water. Environ Sci Technol, 2005, 39: 3314-3320

15 Ponder M S, Helkowski R, Mallouk E T. Continuous flow process for the separation of cesium from complex waste mixtures. Ind Eng Chem Res, 2011, 40: 3384-3389

16 He F, Zhao D Y. Manipulating the size and dispersibility of zerovalent iron nanoparticles by use of carboxymethyl cellulose stabilizers. Environ Sci Technol, 2007, 41: 6216-6221

17 He F, Zhao D Y, Liu J C, et al. Stabilization of Fe-Pd bimetallic nanoparticles with sodium carboxymethyl cellulose for enhanced deg- 
radation of TCE in water. Ind Eng Chem Res, 2007, 46: 29-34

18 Poineau B F, Fattahi M C, Auwer D, et al. Speciation of technetium and rhenium complexes by in situ XAS electrochemistry. Radiochim Acta, 2006, 94: 283-289

19 Maset E R, Sidhu H S, Fisher A, et al. Experimental effect of organic co-contamina on technetium and rhenium speciation and solubility under reducing conditions. Environ Sci Technol, 2006, 40: 5472-5477

$20 \mathrm{Xu} \mathrm{Y,} \mathrm{Zhao} \mathrm{D} \mathrm{Y.} \mathrm{Reductive} \mathrm{immobilization} \mathrm{of} \mathrm{chromate} \mathrm{in} \mathrm{soils} \mathrm{and}$ groundwater by stabilized zero-valent iron nanoparticles. Water Res, 2007, 41: 2101-2108

21 He F, Zhao D Y. Hydrodechlorination of trichloroethene using stabilized Fe-Pd nanoparticles: Reaction mechanism and effects of stabilizers, catalysts and reaction conditions. Appl Catal B, 2008, 84: 533-540

22 Hallam R J, Enans N D M, Jain S L. Sorption of Tc(IV) to some ge- ological materials with reference to radioactive waste disposal. Mineral Mag, 2011, 75: 2439-2448

23 Schrick B, Jennifer L, Blough A, et al. Hydrodechlorination of trichloroethylene to hydrocarbons using bimetallic nickel-iron nanoparticles. Chem Mater, 2002, 14: 5140-5147

24 Lowry G, Johnson K. Congener-specific dechlorination of dissolved PCBs by microscale and nanoscale zerovalent iron in a water/methanol solution. Environ Sci Technol, 2004, 38: 5208-5216

25 Nikolay S, Liana V, Catherine G, et al. Acute toxicity of boron, titanium dioxide, and aluminum nanoparticles to Daphnia magna and Vibrio fischeri. Desalination, 2009, 248: 771-782

26 Liu Y, Majetich S A, Tilton R D, et al. TCE dechlorination rates, pathways, and efficiency of nanoscale iron particles with different properties. Environ Sci Technol, 2005, 39: 1338-1345

Open Access This article is distributed under the terms of the Creative Commons Attribution License which permits any use, distribution, and reproduction in any medium, provided the original author(s) and source are credited. 